\title{
Event memory under naturalistically induced stress
}

\author{
MICHAEL P. TOGLIA \\ State University of New York, Cortland, New York \\ DAVID G. PAYNE \\ State University of New York, Binghamton, New York \\ NARINA L. NIGHTINGALE \\ University of Wyoming, Laramie, Wyoming \\ and \\ STEPHEN J. CECI \\ Cornell University, Ithaca, New York
}

\begin{abstract}
Subjects engaged in intentional and incidental learning tasks while under high or low stress. High stress was induced by leading the subjects to believe that a blood sample was about to be taken; low stress corresponded to no blood sample. Results suggest that intentional and incidental learning are differentially affected by such stress. It is argued that the present methodology is useful for studying the memorial consequences of stress involving the risk of bodily injury.
\end{abstract}

It has long been believed that level of arousal or stress influences task performance. For example, the YerkesDodson law (Yerkes \& Dodson, 1908) indicates that the relationship between stress and performance is curvilinear in nature, with optimal performance associated with moderate levels of arousal. While there has been a great deal of support for this law, a number of departures have been reported (cf. Eysenck, 1979). In a similar vein, the impact of stress/arousal has been examined in situations in which the "task" is memory for a witnessed event. In line with expectations based on the Yerkes-Dodson law, event memory is frequently impaired by experimentally produced high levels of stress or anxiety (e.g., Clifford \& Hollin, 1978; Clifford \& Scott, 1978; Loftus, 1979). Eyewitness accuracy also may be adversely affected for individuals assessed to have high levels of trait and/or state anxiety (e.g., Mueller, Bailis, \& Goldstein, 1979; Siegel \& Loftus, 1978). However, lower levels of stress/arousal are not always associated with eyewitness performance at its best; sometimes accuracy is no worse, or actually better, with high degrees of stress (see Deffenbacher, 1983, for a review).

The fact that a memory-stress relationship has not been established with any consistency is disconcerting given that, in many real-world situations, people witness stressful events (e.g., robberies, car accidents) and later attempt to remember them. In such situations, the stress often is brought on because the person perceives that there is a

Correspondence may be sent to Michael P. Toglia, Department of Psychology, State University of New York, Cortland, P.O. Box 2000, Cortland, NY 13045. chance that he/she may be injured or harmed in some way. Since real-world implications should be the ultimate goal of research regarding the consequences of stress on retention, one must take into account ecological validity considerations. In terms of the situational context, many of the studies noted earlier would receive high marks for realism (i.e., the use of live events or realistic films of an episode). However, as noted by Deffenbacher (1983), in spite of employing ecologically valid events, investigators have generally failed to examine arousal levels that typify those found in stressful events, such as witnessing a crime. For example, those studies that have examined the effects of stress/arousal on memory performance by directly varying arousal have manipulated such factors as noise, temperature, or the degree of violence in films of crime scenes. In other experiments, the approach has been to examine memory performance as a function of individuals' chronic or acute anxiety levels. A potential problem with these approaches is that a subject is unlikely to be experiencing the same type of arousal as is a person in a situation perceived as dangerous.

Accordingly, we were interested in assessing memory for events occurring while there is a possibility that the observer may be harmed or may suffer a painful experience. Toward this end, we established a situation in which a personal fear component was an integral part of an eyewitness event. We employed an analogue of a relatively common real-world situation (donating blood) that is generally viewed as stressful, unpleasant, and involving some painful components. Within this context, we examined performance in both intentional and incidental learning tasks. 


\section{METHOD}

\section{Subjects and Design}

The subjects were 40 Cornell University students who volunteered to participate in a 1-h experimental session. During Phases 1 and 2 of the experiment, the subjects were exposed to two levels of stress (low and high; described below) in a counterbalanced presentation order. The two study phases were followed by a single testing stage (Phase 3 ) that corresponded to the stress level from Phase 1. Thus, there were two between-subjects conditions identified by the stress levels during the two acquisition phases and the final testing phase (i.e., high-low/high vs. low-high/low, for the two study phases and the testing phase).

\section{Procedure}

The subjects were told that we were interested in the "biochemical correlates of cognitive functioning" and that, therefore, there was a chance that a blood sample would be drawn sometime during the experiment. (No blood samples were actually taken.) Throughout the experiment, galvanic skin response (GSR) levels were recorded at 100-msec intervals and averaged every $2.5 \mathrm{sec}$. Each subject's baseline GSR level was determined after the subject was acclimated to the experimental setting and prior to Phase 1 .

The arousal-level manipulations in Phases 1-3 consisted of informing the subject that a blood sample either would (high stress) or would not (low stress) be collected in the next few minutes. At the beginning of Phase 1, the experimenter conveyed to the subject the appropriate information regarding the drawing of a blood sample and covertly signaled a confederate waiting in an adjacent room. The confederate then entered the experimental room, allegedly to determine if a piece of equipment was still broken. During a scripted interaction with the experimenter, the confederate was introduced to the subject and engaged the experimenter in a brief discussion containing several factual statements. This episode was designed to tap incidental learning. The other task in Phase 1 was an intentional list-learning task involving a levelsof-processing manipulation (Craik \& Tulving, 1975). During list presentation, each target word appeared on a CRT, and the subject was required to make either a graphemic, phonemic, or semantic yes/no decision regarding the item. The instructions emphasized both speed and accuracy.

Prior to Phase 2, the experimenter covertly signaled a second confederate, a nurse. She entered the room and, using an appropriate cover story, reversed the stress level from what it had been in Phase 1 . That is, in the high-low/high $(\mathrm{H}-\mathrm{L} / \mathrm{H})$ condition, the nurse said that she was not, after all, going to be able to take a blood sample from the subject. Exactly the reverse occurred in the low-high/low (L-H/L) condition. The nurse, who was present for about $20 \mathrm{sec}$, then left the room, and the subject was given another list to study in the same manner as List 1 , with yes/no decisions required for each item. After the presentation of List 2, the nurse reentered the room and established the appropriate stress levels for Phase 3, the testing phase. The nurse indicated that, due to a change in her schedule, she now would/would not be able to take the blood sample. After this brief (again about $20 \mathrm{sec}$ ) interaction, the subjects were given the following tests: (1) a free recall test for List 1 and then a second one for List 2; (2) a yes/no recognition test for each word list consisting of the 48 target items and 96 distractors, (3) a sixalternative forced-choice photo identification of the nurse, and (4) a cuedrecall test for the scripted episode. The subjects then completed a questionnaire assessing their levels of experience with donating blood, their subjective levels of arousal during the experiment, and the extent to which they believed the cover stories about drawing the blood samples. The subjects then were thoroughly debriefed.

\section{RESULTS}

\section{Arousal Levels}

As expected, there was no significant difference $(p>.05)$ in mean GSR levels between the H-L/H (19.86 micromhos) and the L-H/L (17.06 micromhos) groups during the 10-min baseline acclimation period. Somewhat contrary to our preexperimental expectations, for both conditions, the mean GSR levels continued to increase across the entire experimental session. One possible explanation for this is that the list-learning tasks and the retention tests themselves were fairly stressful and thus produced increases in physiological arousal levels. This admittedly speculative conjecture is consistent with the subjects' comments on the postexperimental questionnaire. (This questionnaire also revealed that the subjects found the cover stories used to manipulate stress levels to be highly credible.)

Since GSR levels increased throughout the entire experiment, it was inappropriate to examine the stress manipulation effects using mean GSR levels in each phase. We therefore calculated the more appropriate measure of the absolute change in GSR levels across successive pairs of phases (i.e., GSR on Phase $\mathbf{N}+1$ minus GSR on Phase N; see Table 1). These data indicated that both groups showed a sizable increase in GSR levels between baseline and Phase 1 . This increase was not significantly different between the two groups, which is consistent with the notion that starting to participate in the experiment was moderately stressful. However, after Phase 1 , the subjects seemed to have "settled in" to the experiment, and the subsequent changes in GSR levels were consistent with expectations based on the stress manipulations. During Phase 2, the $\mathrm{H}-\mathrm{L} / \mathrm{H}$ group was in a low-stress period and showed a slight decline in GSR levels from Phase 1. The L-H/L group (in a high-stress period) showed a sizable increase in GSR levels. The Phase 2 changes in relative GSR levels were significant $[t(30)=2.73, p<.01$, onetailed]. Finally, during Phase 3, the group in the highstress phase (Group $\mathrm{H}-\mathrm{L} / \mathrm{H}$ ) showed a larger increase than did the group in the low-stress phase (Group L-H/L) $[t(30)=1.724, p<.05$, one-tailed $]$.

\section{Intentional Memory Tasks}

The net recall data were analyzed using a 3 (encoding condition) $\times 2$ (group) $\times 2$ (study/test stress congruity, with the first list being congruous and the second being incongruous) ANOVA. As expected, there was a significant main effect of encoding condition $(p<.05)$. There was also a significant main effect of congruity, although it was in the opposite direction from what was expected. The mean recall levels for the congruous lists (List 1) in the $\mathrm{H}-\mathrm{L} / \mathrm{H}$ and $\mathrm{L}-\mathrm{H} / \mathrm{L}$ conditions were 3.13 and 3.42 items, respectively; corresponding recall levels for the incongruous lists (List 2) were 5.06 and 6.89 items, respectively. Note, however, that the retention interval for the incongruous lists was considerably shorter than that for the congruous lists, and, hence, this reverse congruity ef-

Table 1

Mean Change in GSR Levels (in micromhos) Across Phases 1-3

\begin{tabular}{cccc}
\hline Condition & Phase 1 & Phase 2 & Phase 3 \\
\hline H-L/H & +2.53 & -0.09 & +3.59 \\
L-H/L & +3.33 & +2.19 & +2.02 \\
\hline
\end{tabular}


Table 2

Mean Recognition Hit Rate by Group and Stress Congruity as a Function of Encoding Condition

\begin{tabular}{lcccc}
\hline & \multicolumn{4}{c}{ Encoding Condition } \\
\cline { 2 - 5 } Congruity & Graphemic & Phonemic & Semantic & Mean \\
\hline & H-L/H & Group & & \\
Congruous: H/H & .461 & .676 & .762 & .633 \\
Incongruous: L/H & .492 & .623 & .652 & .591 \\
& L-H/L & Group & & \\
Congruous: L/L & .401 & .599 & .615 & .538 \\
Incongruous: H/L & .414 & .522 & .651 & .530 \\
\hline
\end{tabular}

Note- $\mathrm{H}=$ high level of stress. $\mathrm{L}=$ low level of stress.

fect may be attributable to differences in retention interval rather than to study/test congruity. No other main effects or interactions approached significance.

Table 2 shows the mean hit rates for the recognition tests for the three encoding conditions. (There were no significant differences in false-alarm rates among the four groups $\times$ congruity conditions [range $=0.21-0.24]$.) These hit rates were analyzed using the same mixed-factor ANOVA design employed with the recall data. As with recall, a levels-of-processing effect was observed $[F(2,66)=$ $60.87, p<.001$ ], and there were no interactions involving encoding condition.

In contrast to the consistent effect of the orienting task, there were no main effects of either group or congruity, nor did these factors enter into any significant interactions. For the congruous list in each condition, a marginally significant difference $(p=.056)$ was observed between the two groups, with high stress congruity producing better performance than low stress congruity. (This effect was significant, $p<.05$, with a traditional high-threshold corrected recognition measure.) There was no significant difference between groups on the incongruous lists.

The final two tests examined recognition of the nurse and memory for the event with the first confederate. There was no difference between the two groups on the photo identification of the nurse. The latter finding is somewhat intriguing in that, although the subjects saw the nurse for only a very brief period of time, their memory for her were virtually perfect (mean accuracy was greater than $95 \%$ ). Both groups performed reasonably well on the 12 item cued-recall test of the scripted event (mean percent recall was $44.4 \%$ and $48.2 \%$ in the $\mathrm{H}-\mathrm{L} / \mathrm{H}$ and $\mathrm{L}-\mathrm{H} / \mathrm{L}$ conditions, respectively). However, there was no significant difference between the two groups.

\section{DISCUSSION}

The present study provides several insights into the effects of naturalistically induced stress on memory performance. In both recognition and recall, the subjects demonstrated a typical levels-of-processing effect. More importantly, however, the levels effect was not influenced by stress at encoding or retrieval. Similar results have been reported in other studies. For instance, both Mueller, Bailis, and Goldstein (1979) and Mueller, Miller, and Hutchings (1979) observed a standard depthof-processing effect, but no depth $\times$ stress interactions. Thus, there seems to be little support for Schwartz's (1975) contention that highly stressed subjects are less likely to attend to semantic features of verbal items than are low-stress subjects.

Although stress did not "wash out" the effect of depth of processing, it did have important consequences in the experiment. First, in keeping with the idea alluded to earlier that the subjects found the experimental tasks themselves to be fairly stressful, recognition performance was clearly somewhat lower in this experiment than what is normally obtained in episodic memory experiments, and recall levels were nearly at floor. Miller, Mueller, Goldstein, and Potter (1978), using a large number of distractors relative to targets (as in the present study), also found depressed levels of recognition memory. Thus, the stress caused by being in the experiment seems to have lowered performance levels. Second, at first glance, our stress manipulation may seem to be unilluminating since arousal level had no impact on several dependent measures (i.e., recall of the word lists, memory for the scripted event, and identification of the nurse). Although somewhat surprising, these null effects are consistent with Yuille and Cutshall's (1986) field research showing that memory for a real event (a shooting) was not affected by stress at the time of the event.

The recognition results, however, do provide some support for the notion of state dependency in episodic memory. A comparison of the two congruous conditions revealed that List 1 was remembered better in the $\mathrm{H}-\mathrm{L} / \mathrm{H}$ condition than it was in the $\mathrm{L}-\mathrm{H} / \mathrm{L}$ condition. Note, however, that the GSR data indicated that both groups were under the same (high) level of stress in Phase 1. At testing (Phase 3), however, there was a significant difference in the stress levels $(\mathrm{H}-\mathrm{L} / \mathrm{H}>\mathrm{L}-\mathrm{H} / \mathrm{L})$. According to this analysis, then, the $\mathrm{L}-\mathrm{H} / \mathrm{L}$ group was functionally operating as an $\mathrm{H}-\mathrm{H} / \mathrm{L}$ group, and, thus, the study/test conditions for this condition on List 1 were incongruous and, consequently, performance levels were less than those in the congruous $\mathrm{H}-\mathrm{L} / \mathrm{H}$ condition. Compatible with this interpretation is the finding that the two groups produced equivalent recognition levels on List 2, for which, according to the GSR data, both groups suffered from a mismatch between encoding and testing states.

The difference in Phase 1 recognition rates was not paralleled in the incidental learning task from Phase 1 (i.e., the scripted event). One plausible explanation for this discrepancy (i.e., intentional vs. incidental) is provided by Deffenbacher (1983), who argued that such inconsistent results with stress effects may be due to differences in the complexity of various learning tasks. Finally, we concur with Sanders's (1983) view that different stressors can affect different cognitive processes. Thus, the effects of stress on memory will depend upon the specific stressor and the cognitive processes utilized in the memory task. Nevertheless, we believe that the research methodology employed in this study holds considerable promise for investigating the memorial consequences of stress induced by fear of bodily injury.

\section{REFERENCES}

Clifford, B. R., \& Holuin, C. R. (1978). Experimentally manipulated arousal and eyewitness testimony. Unpublished manuscript.

Clifford, B. R., \& SCOTT, J. (1978). Individual and situational factors in eyewitness testimony. Journal of Applied Psychology, 63, 352-359.

Craik, F. I. M., \& Tulving, E. (1975). Depth of processing and the retention of words in episodic memory. Journal of Experimental Psychology: General, 104, 268-294.

DefFenbaCher, K. A. (1983). The influence of arousal on reliability of testimony. In S. M. A. Lloyd-Bostock \& B. R. Clifford (Eds.), Evaluating witness evidence (pp. 235-251). New York: Wiley.

EySENCK, M. W. (1979). Anxiety, learning, and memory: A reconceptualization. Journal of Research in Personality, 13, 363-385.

LofTus, E. F. (1979). Eyewitness testimony. Cambridge, MA: Harvard University Press.

Miller, D. J., Mueller, J. H., Goldstein, A. G., \& Potter, T. L. (1978). Depth of processing and test anxiety in landscape recognition. Bulletin of the Psychonomic Society, 11, 341-343.

Mueller, J. H., Bailis, K. L., \& Goldstein, A. G. (1979). Depth 
of processing and anxiety in facial recognition. British Journal of Psychology, 70, 511-515.

Mueller, J. H., Miller, D. J., \& Hutchings, J. L. (1979). Anxiety and orienting tasks in picture recognition. Bulletin of the Psychonomic Society, 13, 145-148.

SANDERS, A. F. (1983). Towards a model of stress and human performance. Acta Psychlogica, 53, 61-97.

SCHWARTZ, S. (1975). Individual differences in cognition: Some relationships between personality and memory. Journal of Research in Personality, 9, 217-225.
SIEgEL, J. M., \& Loftus, E. F. (1978). Impact of anxiety and life stress upon eyewitness testimony. Bulletin of the Psychonomic Society, 12, 479-480.

YERKES, R. M., \& DoDson, J. D. (1908). The relation of strength of stimulus to rapidity of habit formation. Journal of Comparative Neurology \& Psychology, 18, 459-482.

Yuille, J. C., \& Cutshall, J. L. (1986). A case study of eyewitness memory of a crime. Journal of Applied Psychology, 71, 291-301.

(Manuscript received April 24, 1989.)

\title{
Announcement
}

\author{
19th Annual Meeting of the Society for Computers in Psychology \\ Atlanta, Georgia \\ November 16, 1989
}

The 19th Annual Meeting of the Society for Computers in Psychology will be held at the Hyatt Regency Hotel in Atlanta, Georgia on November 16, 1989. As usual, this meeting will feature papers on applications of computers to all areas of psychology-experimental, clinical, and educational.

For further information, contact Paula Goolkasian, Department of Psychology, University of North Carolina at Charlotte, Charlotte, NC 28223. 